\title{
Urethral pseudodiverticulum secondary to penile fracture and complete urethra dissection
}

\author{
Giovanni B. Di Pierro, MD; Luca lannotta, MD; Michele Innocenzi, MD; Gulia Caterina, MD; Pietro Grande, MD; \\ Cristiano Cristini, MD; Vincenzo Gentile
}

Department of Scienze Ginecologico-Ostetriche e Scienze Urologiche, Sapienza University, Rome, Italy

Cite as: Can Urol Assoc J 2013;7(5-6):e347-50. http://dx.doi.org/10.5489/cuaj.1209

Published online May 13, 2013.

\section{Abstract}

A 22-year-old man reported cracking sound and acute pain during sexual intercourse followed by rapid penile detumescence and ecchymosis. He experienced more pain because he could not urinate and had a palpably full bladder. Moreover, his urethra was bleeding. Physical examination revealed swollen, ecchymotic and deviated penis and penis ultrasonography showed an injury of the tunica albuginea and Buck's fascia with an expanding hematoma. Suprapubic catheter was positioned. Surgical exploration revealed a tear of tunica albuginea of both corpora cavernosa and complete urethral dissection. End-to-end urethral anastomosis and suture of corpora cavernosa lesion were performed. Vescical catheter was mantained for 6 days and suprapubic catheter for 3 months to allow a complete urethral healing. A pseudodiverticulum was found at anastomosis level on the urethrocistography 1 month after surgery. It disappeared by allowing micturition via the suprapubic catheter. The patient presented regular urinary flow and physiological erections 30 days later. In our experience, prompt surgical repair preserved erectile function and keeping the suprapubic catheter protected the urethra; this was the correct management for repairing the urethral lesion.

\section{Introduction}

Penile fracture involves an erect penis and is caused by tearing or cracking the corpora cavernosa. ${ }^{1}$ It may be associated with urethra rupture and injury of the dorsal nerve and vessels. Sexual intercourse is the most common cause, though masturbation has also been reported as a cause. At the time of injury, patients typically notice a cracking sound and penile pain, associated with a sudden loss of erection and/or hematuria. ${ }^{2}$ Tunica albuginea is one of the strongest fascia in the human body, but it significantly stretches during erection (it is up to $2.4 \mathrm{~mm}$ thick in the flaccid state, but becomes as thin as 0.25 to $0.5 \mathrm{~mm}$ during erection).
An intracorporal pressure of $1500 \mathrm{mmHg}$ or more during erection may tear the tunica albuginea., ${ }^{1,2}$

\section{Case report}

A 22-year-old man presented to the emergency department with a history of sudden cracking sound and acute pain during sexual intercourse followed by rapid detumescence, penile swelling and ecchymosis. Pain was increased by the impossibility to urinate; therefore he had a palpably full bladder. Moreover, his urethra was bleeding. Physical examination revealed swollen, ecchymotic and deviated penis. Penis ultrasonography showed injury of the tunica albuginea and Buck's fascia and expanding hematoma.

Suprapubic catheter was positioned to empty the bladder. The patient underwent immediate surgical exploration and repair of the fracture. This repair was performed through circumferential subcoronal incision; degloving and hematoma evacuation were carried out showing a tear of the tunica albuginea of both corpora cavernosa and complete urethral dissection (Fig. 1, part a). After minimal debridement and mobilization of proximal and distal corpus spongiosum, the urethra was spatulated. Two $2 / 0$ Vicryl interrupted sutures were used to repair the lesion, performing a $\mathrm{T}$ - $\mathrm{T}$ anastomosis on one single layer by tension-free fashion (Fig. 1,part b). A 18 Ch Foley catheter was inserted and maintained for 6 days. In the end, a containment bandage was positioned by Fisto-Blok. Patient was given antibiotic and anti-edema therapy. A simildiverticular formation was found at the T-T anastomosis level by dynamic and mintional ultrasonographic exam 1 month after surgery. This entity was confirmed by mintional urethrocistography like a ventral spreading of contrast (Fig. 2, part a). For this reason, the suprapubic catheter was maintained for an additional month and micturition was permitted with this device. Two months after surgery, the uretrocistography exam showed complete disappearance of contrast spreading and the development of a stricture at the T-T anastomosis level (Fig. 2, part b). During the subsequent follow-up, the patient presented 


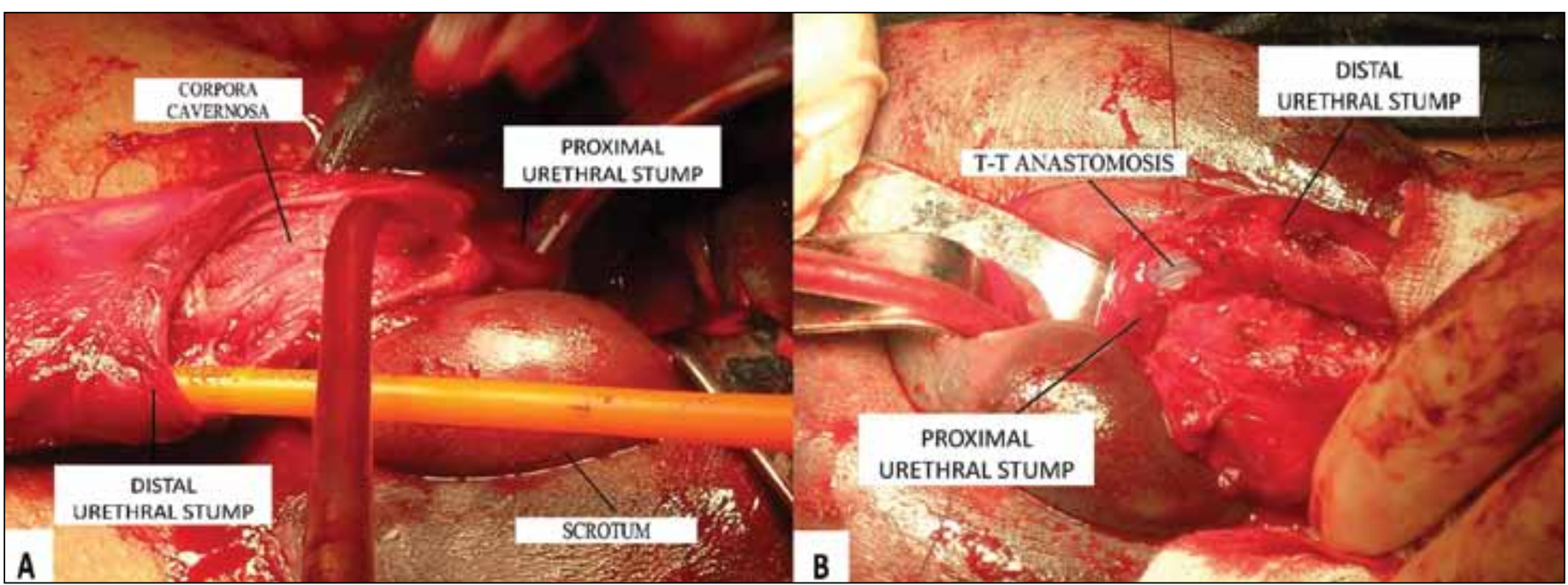

Fig. 1. A: Tear of the tunica albuginea of both corpora cavernosa and complete urethral dissection. B: Urethral end-to-end anastomosis performed by tension-free interrupted sutures.

normal uroflowmetry (QMax $17.4 \mathrm{~mL} / \mathrm{sec}$; Vcomp $250 \mathrm{~mL}$ ) after restarting micturition "per uretram," but the suprapubic catheter was maintained for other 20 additional days. The 3-month uroflowmetry showed a Qmax of $20.3 \mathrm{~mL} / \mathrm{sec}$ and the patient reported normal spontaneous erections and he resumed sexual activity 4 months later.

\section{Discussion}

Erection converts the safe, flaccid penis into a vulnerable organ and the tunica thins out from $2.4 \mathrm{~mm}$ to 0.5 to
$0.25 \mathrm{~mm} .^{1,2}$ It requires a pressure in excess of $1500 \mathrm{mmHg}$ to achieve rupture. ${ }^{3-5}$ Sexual intercourse and penile manipulation are the most common causes of penile fracture.

Cavernosography may be performed to find the tear in the tunica albuginea, but it may present false negative results because of blood clot formation at the defect level. Penile ultrasound can be used to assist the diagnosis of penile fracture; it can be easily performed, is non-invasive and useful in determining localized sub-Buck's fascia hematoma due to injury or to causes other than tunical tear. ${ }^{6}$ Also magnetic resonance (MR) imaging is potentially useful to assess the

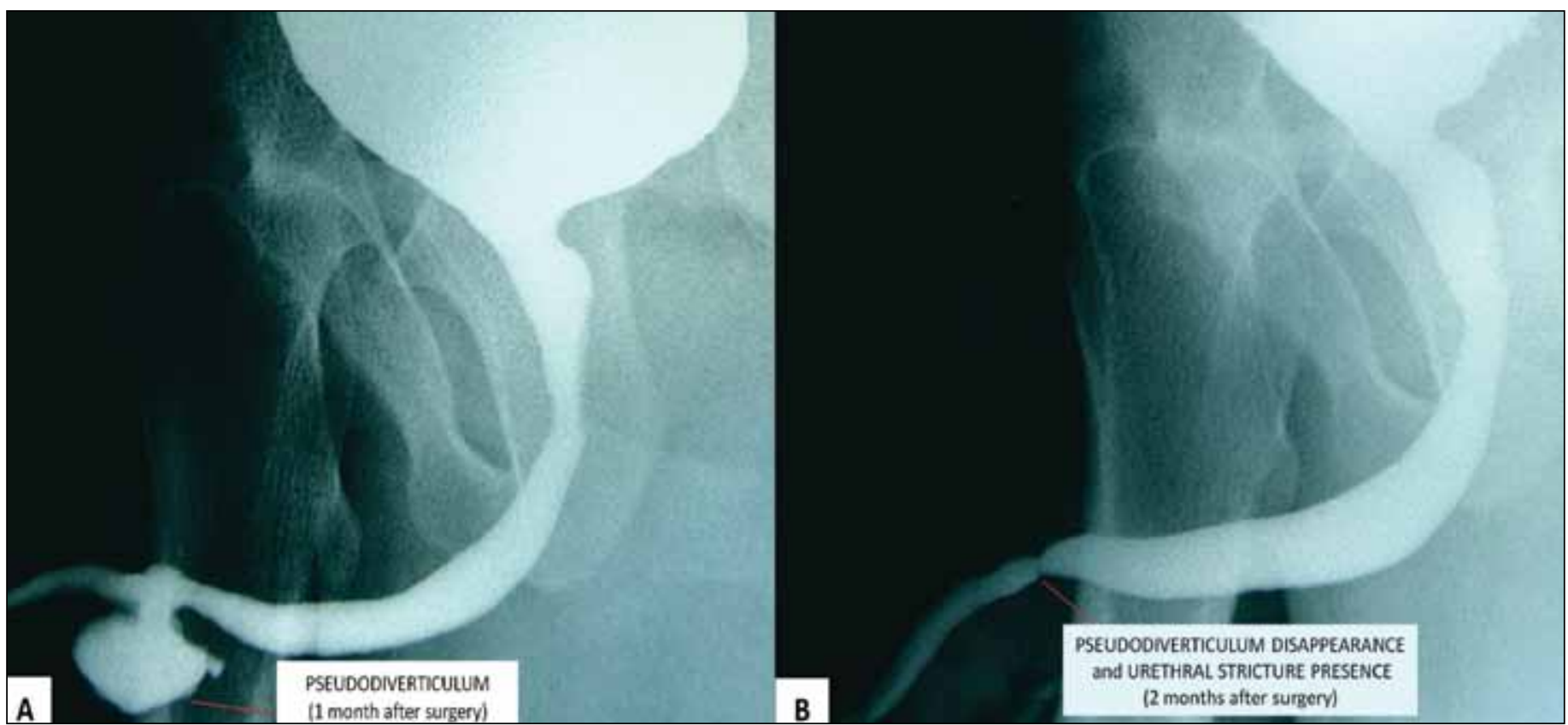

Fig. 2. A: Mintional urethrocistography showing a ventral spreading of contrast. B: Uretrocistography showing complete disappearance of contrast spreading and presence of a stricture at the anastomosis level. 
penile rupture; the key finding is disruption of the low-signal intensity tunica albuginea, which is well-seen on both T1 and $\mathrm{T} 2$ weighted images, although $\mathrm{T} 1$ weighted sequences may detect more subtle fractures.

Treatment may be either conservative or immediate surgery. The conservative management of penile fracture includes splinting, cold compresses and a combination of anti-inflammatory, analgesic medication and fibrinolytics. However, long-term outcomes for conservative management demonstrated significant complication rates, such us curved or painful erection, erectile dysfunction, artero-venous fistula, infection and plaque formation (like Peyronie's syndrome). Comparing surgery and conservative management in 42 patients, Yapanoglu and colleagues observed complications in $0.8 \%$ to $2 \%$ and $10 \%$ to $40.7 \%$, respectively. Similarly, other authors suggest early surgical repair as standard treatment, observing different rates of urethral injuries. $^{6,9-17}$ After immediately repairing 322 penile fractures, Derouiche and colleagues reported only 10 urethral sections. ${ }^{6}$ Zaargoshi, however, showed an incidence of urethral lesion with corpora cavernosa fracture of $38 \%$ and the absence of these features did not exclude the possibility of urethral involvement. ${ }^{9}$

Another study reported on 15 patients who underwent immediate surgical exploration; 4 of these had urethral injuries with no complications at 7.5 month follow-up. This underlines the fact that further evaluation beyond historytaking and a clinical examination are not necessarily useful. ${ }^{10}$ Moreno Sierra and colleagues claim that complementary tests, such as ultrasound, are helpful but not definitive in their experience with emergency surgical repair on 15 patients (only 1 case with complete urethral fracture). ${ }^{11}$ In 14 patients with concomitant urethral rupture treated surgically, El-Assmy and colleagues reported no harmful long-term sequelae on urethral and erectile function in most patients and only one relative urethral narrowing post-surgery. ${ }^{12}$

Several techniques have been proposed, such as penile degloving (with circumferential or subcoronal incision); longitudinal incision over the haematoma; inguinoscrotal incision; high-scrotal midline incision on the raphe; and suprapubic incision. We preferred the subcoronal circumferential incision with penis degloving because of the excellent exposure of corpora cavernosa and urethra, which allowed to detect accidental urethral injuries (in our case the ultrasound did not detect urethral rupture).

In our experience (15 cases in 5 years), penile fracture occurred during vigorous sexual intercourse, but the urethra was never compromised. The latest may be suspected when voiding difficulty is present or with hamaturia and/or blood from the meatus. Moreover, our patient reported a pseudodiverticulum formation on the uretrocistography showing a ventral contrast spreading. To our knowledge, this is the first case to be reported in the literature. Functional rest allowed a complete disappearance of leakage and urethra healing with persistence of a slight stricture at T-T anastomosis controlled by uroflowmetry during the subsequent follow-up. This finding changed our management because it did not reveal a post-surgery diverticulum.

\section{Conclusion}

Penile fracture is a urological emergency. An effective diagnosis of penile fracture can be based on medical history, physical examination and imaging tests, such as ultrasound and magnetic resonance imaging. In our experience, prompt surgical repair preserved erectile function and keeping suprapubic catheter protected the urethra.

Competing interests: None declared.

This paper has been peer-reviewed.

\section{References}

1. Eke N. Fracture of the penis. Br J Surg 2002;89:555-65. http://dx.doi.org/10.1046/i.13652168.2002.02075.x

2. McEleny K, Ramsden P, Pickard R. Penile fracture. Nat Clin Pract Urol 2006;3:170-4. http://dx.doi. org/10.1038/ncpuro0433

3. Bitsch M, Kromann-Andersen B, Schou J, et al. The elasticity and the tensile strength of tunica albuginea of the corpora cavernosa. J Urol 1990; 143:642-5.

4. De Rose AF, Giglio M, Carmignani G. Traumatic rupture of the corpora cavernosa: new physiopathologic acquisitions. Urology 2001;57:319-22. http://dx.doi.org/10.1016/S0090-4295(00)00926-2

5. Jagodic K, Erklavec $M$, Bizjak I, et al. A case of penile fracture with complete uretra distruption during sexual intercourse: a case report. J Med Case Rep 2007;1:14. http://dx.doi.org/10.1186/1752-1947-1-14

6. Derouiche A, Belhaj K, Hentati $\mathrm{H}$, et al. Management of penile fractures complicated by urethral rupture. Int I Impot Res 2008;20:111-4. Epub 2007 Aug 2. http://dx.doi.org/10.1038/si.jiir.3901599

7. Kirkham AP, Illing RO, Minhas $S$, et al. MR imaging of nonmalignant penile lesions. Radiographics 2008;28:837-53. http://dx.doi.org/10.1148/rg.283075100

8. Yapanoglu T, Aksoy Y, Adanur $S$, et al. Seventeen years' experience of penile fracture: conservative vs. surgical treatment. J Sex Med 2009;6:2058-63. Epub 2009 Apr 28. http://dx.doi.org/10.1111/ j.1743-6109.2009.01296.x

9. Zargooshi J. Penile fracture in Kermanshah, Iran: the long-term result of surgical treatment. BJU Int 2002;89:890-4. htrp://dx.doi.org/10.1046/i.1464-410X.2002.02745.x

10. Agarwal MM, Singh SK, Sharma DK, et al. Fracture of the penis: a radiological or clinical diagnosis? A case series and literature review. Can J Urol 2009;16:4568-75.

11. Moreno Sierra J, Garde Garcia H, Fernandez Perez C, et al. Surgical repair and analysis of penile fracture complications. Urol Int 2011;86:439-43. Epub 2011 Apr 7. http://dx.doi.org/10.1159/000324249

12. El-Assmy A, El-Tholoth HS, Mohsen T, et al. Long-term outcome of surgical treatment of penile fracture complicated by urethral rupture. J Sex Med 2010;7:3784-8. http://dx.doi.org/10.1111 /i.1743-6109.2009.01653

13. Gamal WM, Osman MM, Hammady A, et al. Penile fracture: long-term results of surgical and conservative management. J Trauma 2011;71:491-3. http://dx.doi.org/10.1097/TA.0b013e3182093113

14. el-Assmy A, el-Tholoth HS, Mohsen T, et al. Does timing of presentation of penile fracture affect outcome of surgical intervention? Urology 2011;77:1388-91. Epub 2011 Mar 25. http://dx.doi.org/10.1016/i. urology.2010.12.070

15. Kamdar C, Mooppan UM, Kim H, et al. Penile fracture: preoperative evaluation and surgical technique for optimal patient outcome. BJU Int 2008;102:1640-4; discussion 1644. Epub 2008 Aug 14. http:// dx.doi.org/10.1111/i.1464-410X.2008.07902.x 
Di Pierro et al.

16. Al-Shaiii TF, Amann J, Brock GB. Fractured penis: diagnosis and management. J Sex Med 2009;6:323140. http://dx.doi.org/10.1111/i.1743-6109.2009.01593.x

17. Mazaris $E M$, Livadas $K$, Chalikopoulos $D$, et al. Penile fractures: immediate surgical approach with a midline ventral incision. BJU Int 2009;104:520-3. Epub 2009 Feb 23. http://dx.doi.org/10.1111/i.1464410X.2009.08455.x
Correspondence: Dr. Giovanni B. Di Pierro, Department of Scienze Ginecologico-Ostetriche e Scienze Urologiche, Sapienza University, Rome, Italy; gb.dipierro@libero.it 